\title{
Pressure drop prediction in annular two-phase flow in macroscale tubes and channels
}

DOI:

10.1016/j.ijmultiphaseflow.2016.11.003

\section{Document Version}

Accepted author manuscript

Link to publication record in Manchester Research Explorer

\section{Citation for published version (APA):}

Cioncolini, A., \& Thome, J. (2017). Pressure drop prediction in annular two-phase flow in macroscale tubes and channels. International Journal of Multiphase Flow, 89, 321-330.

https://doi.org/10.1016/j.ijmultiphaseflow.2016.11.003

\section{Published in:}

International Journal of Multiphase Flow

\section{Citing this paper}

Please note that where the full-text provided on Manchester Research Explorer is the Author Accepted Manuscript or Proof version this may differ from the final Published version. If citing, it is advised that you check and use the publisher's definitive version.

\section{General rights}

Copyright and moral rights for the publications made accessible in the Research Explorer are retained by the authors and/or other copyright owners and it is a condition of accessing publications that users recognise and abide by the legal requirements associated with these rights.

\section{Takedown policy}

If you believe that this document breaches copyright please refer to the University of Manchester's Takedown Procedures [http://man.ac.uk/04Y6Bo] or contact uml.scholarlycommunications@manchester.ac.uk providing relevant details, so we can investigate your claim.

\section{OPEN ACCESS}




\title{
Title
}

Pressure drop prediction in annular two-phase flow in macroscale tubes and channels

\section{Authors \& Affiliation}

Andrea Cioncolini [corresponding]

School of Mechanical, Aerospace and Civil Engineering, University of Manchester, George Begg

Building, Sackville Street, M1 3BB Manchester, United Kingdom

Tel: +44.161.306.3711, e-mail: andrea.cioncolini@manchester.ac.uk

John R. Thome

Heat and Mass Transfer Laboratory, Swiss Federal Institute of Technology-EPFL, EPFL-STI-IGM-

LTCM, Station 9, 1015 Lausanne, Switzerland.

Tel: +41.21.693.5981, e-mail: john.thome@epfl.ch

\begin{abstract}
A new prediction method for the frictional pressure drop in annular two-phase flow is presented. This new prediction method focuses on the aerodynamic interaction between the liquid film and the gas core in annular flows, and explicitly takes into account the asymmetric liquid film distribution in the tube cross section induced by the action of gravity in horizontal tubes operated at low mass fluxes. The underlying experimental database contains 6291 data points from the literature with 13 fluid combinations (both single-component saturated fluids such as water, carbon dioxide and refrigerants R12, R22, R134a, R245fa, R410a, R1234ze, and two-component fluids such as water-argon, water-nitrogen, alcohol-argon, water plus alcohol-argon and water-air), vertical and horizontal tubes and annuli with diameters from 3 $\mathrm{mm}$ to $25 \mathrm{~mm}$, and both adiabatic and evaporating flow conditions. The new prediction method is very simple to implement and use, is physically based and outperforms existing pressure drop correlations (mean absolute error of $12.9 \%$, and 7 points out of 10 captured to within $\pm 15 \%$ ).
\end{abstract}




\section{Keywords}

Annular two-phase flow; Pressure drop; Pressure gradient; Shear-driven liquid film; Aerodynamic interaction; Evaporation;

\section{Introduction}

Annular flow is one of the most important and frequently encountered flow regimes in gas-liquid and vapor-liquid two-phase flows in tubes and channels. In annular flow, a thin film of liquid flows along the channel wall, surrounding a central gas or vapor core that flows in the center of the channel carrying entrained liquid droplets in suspension. The gas core, which flows faster than the liquid film, drags the liquid film along the tube wall and continuously atomizes the tips of the waves that are formed at the liquid film surface, while entrained liquid droplets are continuously deposited back onto the liquid film after being accelerated in the gas or vapor core. This continuous exchange of liquid between the liquid film and the gas or vapor core yields a tight mass and linear momentum coupling between the phases, which makes the physics of annular flows very rich and their analysis and modeling particularly challenging.

Notwithstanding the extensive investigations carried out to date, mostly driven by nuclear reactor cooling applications, annular flows are still actively studied in the nuclear industry as more accurate and reliable prediction methods are required for several cutting-edge applications, such as nuclear reactor fuel optimization, nuclear reactor power uprates and license extensions, and nuclear systems transient and safety analysis. Additional practical applications where the accurate modeling of annular two-phase flow is critical include air conditioning and refrigeration systems, energy conversion systems, chemical processing plants, and high heat flux cooling applications such as nuclear fusion reactors and power electronics.

The accurate prediction of the pressure drop is crucial for a sound design and energy efficient operation of virtually any two-phase flow system. Moreover, the wall shear stress is typically required as input in the modeling of mass, linear momentum and heat transport in two-phase flows, and this in turn requires the knowledge of the pressure drop. Recently, Cioncolini et al. (2009b) proposed a pressure drop prediction method specifically designed for annular two-phase flows. In their method for macroscale tubes the twophase frictional pressure gradient is calculated as follows: 
$\left(\frac{d P}{d z}\right)_{f r}=\frac{4 \tau_{w}}{d}=2 f_{t p} \frac{\rho_{c} V_{c}^{2}}{d}$

where $\tau_{w}$ is the wall shear stress, $d$ is the tube diameter and the two-phase Fanning friction factor $f_{t p}$ is expressed as function of the core flow Weber number $W e_{c}$ :

$f_{t p}=0.172 W e_{c}^{-0.372}$

$W e_{c}=\frac{\rho_{c} V_{c}^{2} d_{c}}{\sigma}$

where $\sigma$ is the surface tension. The droplet-laden core flow density $\rho_{c}$, average velocity $V_{c}$ and diameter $d_{c}$ are defined as:

$\rho_{c}=\left(1-\varepsilon_{c}\right) \rho_{l}+\varepsilon_{c} \rho_{g}$

$V_{c}=\frac{4}{\pi} \frac{\lfloor x+e(1-x)\rfloor \Gamma}{\rho_{c} d_{c}^{2}}$

$d_{c}=d-2 t=d \sqrt{\varepsilon+\gamma-\varepsilon \gamma}$

where $\rho_{l}$ and $\rho_{g}$ are the liquid and vapor densities, $x$ is the vapor quality, $\Gamma$ is the total mass flow rate, $e$ is the entrained liquid fraction, $t$ is the average liquid film thickness, and $\varepsilon_{c}$ is the core flow void fraction:

$$
\varepsilon_{c}=\frac{\varepsilon}{\varepsilon+\gamma(1-\varepsilon)}
$$

The liquid droplet hold-up $\gamma$ is estimated neglecting the slip between the entrained liquid droplets and the carrier gas phase as follows:

$\gamma=e \frac{\varepsilon}{1-\varepsilon} \frac{1-x}{x} \frac{\rho_{g}}{\rho_{l}}$

The void fraction $\varepsilon$ and the entrained liquid fraction $e$ are predicted using the methods of Woldesemayat and Ghajar (2007) and Oliemans et al. (1986), respectively, as described in Cioncolini et al. (2009b). Besides outperforming existing pressure drop correlations, as described by the authors, a significant advantage of the method described above with respect to other prediction methods is that the two-phase friction factor in Eq. (2) is based on a single dimensionless group, the core flow Weber number $W e_{c}$, which is physically plausible in the context of annular flows. In fact, the Weber number is widely used in the analysis of multiphase flows, and is in particular a controlling dimensionless group in spray theory in 
general, in the analysis of liquid atomization and in the study of wave formation and atomization on shear-driven liquid films, so that it is clearly physically relevant in the analysis of annular flows. The experimental databank used to derive Eq. (2) contained 3030 data points for 6 different fluid combinations (water-steam, water-argon, water-nitrogen, alcohol-argon, water plus alcohol-argon, and water-air) flowing adiabatically through vertical circular tubes with diameters from $4.90 \mathrm{~mm}$ to $31.7 \mathrm{~mm}$. Although this experimental databank was quite large, it is essentially limited to adiabatic water mixtures and vertical circular tubes. Besides, notwithstanding the formal simplicity of Eq. (2), the application of the prediction method in Eqs. (1)-(8) is actually rather involved, and this formal complexity might limit the applicability of the method into existing computer programs.

The purpose of the present study is to improve the annular flow pressure drop prediction method proposed in Cioncolini et al. (2009b) that was briefly described above. In particular, the method is here extended to cover evaporating flow conditions, non-circular channels (annuli), and horizontal annular flows at low mass fluxes where gravity induces a partial stratification of the phases, and the liquid film is therefore asymmetrically distributed along the tube perimeter (thinner at the tube top and tube sides, and thicker at the tube bottom). Moreover, the method has been strongly simplified in its formulation and recently developed and more accurate closure laws have been implemented to predict the void fraction and the entrained liquid fraction. The underlying experimental databank has been significantly expanded from the 3030 data points initially used by Cioncolini et al. (2009b) and now contains 6291 data points that cover water, water mixtures, carbon dioxide and refrigerants flowing in vertical and horizontal tubes and channels under both adiabatic and evaporating flow conditions. As will be shown, this new improved annular flow pressure drop prediction method is physically sound, is very simple to implement and use, and is superior in accuracy to existing pressure drop correlations. This new pressure drop prediction method is part of the unified annular flow modeling suite that is currently being developed by the authors (Cioncolini et al., 2009a, 2009b, 2015; Cioncolini and Thome, 2010, 2011, 2012a, 2012b, 2013, 2016; Mauro et al., 2014; Thome and Cioncolini, 2016). The great advantage of a unified suite of prediction methods is that all the models included are formulated consistently and are proven to work well together, thus providing a framework for analysis, modeling and future development.

In what follows, the experimental pressure drop databank is presented first, followed by the description of the new pressure drop prediction method. 


\section{Experimental database description}

The main details regarding the experimental pressure drop databank collected from the literature for use here are summarized in Table 1, while a selection of histograms that further describes the collected data is shown in Fig. 1. The database includes 6291 measurements of the pressure drop collected from 13 different literature studies that cover 13 different vapor-liquid and gas-liquid combinations (both singlecomponent saturated fluids such as water, carbon dioxide and refrigerants R12, R22, R134a, R245fa, R410a, R1234ze, and two-component fluids such as water-argon, water-nitrogen, alcohol-argon, water plus alcohol-argon and water-air). As can be seen in Table 1, the databank covers vertical upflow (74\% of the data) and horizontal flow ( $26 \%$ of the data), adiabatic ( $80 \%$ of the data) and evaporating ( $20 \%$ of the data) flow conditions, and both circular tubes ( $91 \%$ of the data) and annuli (9\% of the data). Water accounts for $44 \%$ of the collected databank, while water mixtures and refrigerants account for $30 \%$ and $26 \%$ of the collected data, respectively. The databank covers tube diameters and annuli hydraulic diameters in the range of $3 \mathrm{~mm}$ to $25 \mathrm{~mm}$, so that the present study is limited to macroscale tubes and channels (microscale tubes and microchannels will be addressed in a future study). In particular, the databank includes pressure drop data generated at high mass flux with and without heat addition, which are of interest for high heat flux cooling applications, and pressure drop data generated at low mass flux in horizontal tubes, which are relevant for air conditioning and refrigeration applications.

As noted by Levy (1999), the transition from intermittent to annular flow typically corresponds to a void fraction of about $\approx 0.7$. As can be seen in Fig. 1 , all the data collected in Table 1 correspond to a void fraction (estimated at the inlet of the test section) above 0.6 and the vast majority of the data are actually above 0.7 . As such, the contamination of the collected data from intermittent flow can be expected to be minimal, and is therefore neglected in the present study. In this study, in particular, the void fraction $\varepsilon$ is predicted according to the annular flow method of Cioncolini and Thome (2012b):

$$
\varepsilon=\frac{h x^{n}}{1+(h-1) x^{n}}
$$

where the dimensionless parameters $h$ and $n$ are functions of the gas to liquid density ratio $\rho_{g} \rho_{l}^{-1}$ : 
$h=-2.129+3.129\left(\rho_{g} \rho_{l}^{-1}\right)^{-0.2186}$

$n=0.3487+0.6513\left(\rho_{g} \rho_{l}^{-1}\right)^{0.5150}$

The relevance of compressibility effects in the pressure drop data collected in Table 1 is checked using the multiphase Mach number $M$ defined as:

$M=\frac{V_{t p f}}{a_{t p f}} \approx \frac{V_{g}}{a_{g}}=\frac{x G}{\rho_{g} \varepsilon a_{g}}$

where $V_{t p f}$ is the average velocity for the two-phase flow, which is approximated in Eq. (11) with the gas velocity $V_{g}$ calculated in a segregated-phase approximation, while $a_{t p f}$ is the sonic velocity for the twophase flow, which is approximated in Eq. (11) with the gas sonic velocity $a_{g} . G$ is the total mass flux. Since entrained liquid droplets are neglected, $V_{g}$ provides a slight upperbound to the actual two-phase flow velocity. On the other hand, available measurements of the sonic velocity in high pressure steamwater annular flows give sonic velocities slightly higher than those of single-phase gas flow (Tong and Weisman, 1996), so that the gas sonic velocity $a_{g}$ can be expected to provide a lowerbound to the sonic velocity of an annular two-phase flow. Therefore, Mach number values predicted with Eq. (11) can be expected to be slightly conservative, i.e. Eq. (11) approximates the 'true' Mach numbers from above. As can be seen in Fig. 1, all data points in Table 1 are characterized by Mach number values below about 0.2. Assuming that the same Mach number threshold of $M \approx 0.3$ normally used in single-phase incompressible flow problems can be applied to two-phase annular flows as well, compressibility effects are therefore neglected.

As can be seen in Fig. 1, the inclusion in the databank of several fluids and different operating conditions yields quite large variations of the thermophysical properties of the fluids. In particular, the gas to liquid density ratio $\rho_{g} \rho_{l}^{-1}$ spans about two orders of magnitude from 0.0029 to 0.171 , the gas to liquid viscosity ratio $\mu_{g} \mu_{l}^{-1}$ spans almost two orders of magnitude from 0.0166 to 0.236 , while the surface tension $\sigma$ variation is from $0.0024 \mathrm{Nm}^{-1}$ to $0.0733 \mathrm{Nm}^{-1}$.

It is well known that in horizontal tubes, when the hydrodynamic conditions are appropriate, annular flows can become asymmetric with respect to the tube axis due to the effect of gravity. In particular, the liquid in the annular film tends to drain down the tube wall under the action of gravity, yielding an asymmetric liquid film distribution in the tube cross section characterized by a thin liquid film at the tube top and a thicker liquid film at the tube bottom. Notably, based on available data (Cioncolini and Thome, 
2013) the liquid film at the tube bottom can be up to 100 times thicker than the liquid film at the tube top.

As they explained, the degree of asymmetry in the liquid film distribution in the tube cross section can be estimated with the multiphase Froude number $F r$ defined as follows:

$$
F r=\frac{J_{g}}{\sqrt{g d}} \sqrt{\frac{\rho_{g}}{\rho_{l}-\rho_{g}}}
$$

where $g$ is the acceleration of gravity and $J_{g}$ is the superficial gas velocity:

$$
J_{g}=\frac{x G}{\rho_{g}}
$$

In particular, horizontal annular flows characterized by a multiphase Froude number above $\mathrm{Fr}>10$ can be considered axially symmetric, while Froude number values below $F r=10$ denote asymmetric liquid film distribution, where the lower the multiphase Froude number value the higher the degree of asymmetry in the liquid film. As can be seen in Fig. 1, therefore, only a small subset of the horizontal annular flow data collected in Table 1 can be regarded as axially symmetric, and significant liquid film asymmetry is present in the majority of the horizontal flow data collected. In general, this asymmetrical effect is ignored by existing two-phase frictional pressure drop methods, and hence is probably one of the reasons limiting their reliability.

In the next paragraph, the new annular flow pressure drop prediction method will be designed using the adiabatic flow data collected in Table 1 (5057 data points), generated with circular tubes and annuli in horizontal and vertical channels. Successively, the new pressure drop prediction method will be extended to evaporating flows using the additional data in Table 1 for evaporation in vertical tubes and annuli (1234 data points).

\section{New prediction method}

It stands to reason that the fluid dynamics of annular flows is largely controlled by the aerodynamic interaction between the liquid film and the gas core. In particular, the gas core can be regarded as a confined spray composed by the gas or vapor phase and the entrained liquid droplets that flow in the center of the channel, dragging and atomizing the annular liquid film that streams along the channel wall. The flow in the liquid film is therefore shear-driven, and the energy required to drag and atomize the liquid film is provided in the form of kinetic energy by the core flow. Accordingly, the very simple 
modeling approach for the fluid-structure interaction in annular flows that is proposed here reads as follows:

$$
\begin{aligned}
& \tau_{w}=\tau_{w}(\rho, V, L, \sigma) \quad \text { Vertical upflow } \\
& \tau_{w}=\tau_{w}(\rho, V, L, \sigma, g) \text { Horizontal flow }
\end{aligned}
$$

where $\rho, V$ and $L$ are a characteristic density, a characteristic velocity and a characteristic length for the annular flow, as yet to be determined. The aerodynamic interaction between the liquid film and the gas core is controlled by the competition between the disrupting aerodynamic force and the surface tension retaining force. In Eqs. (14) and (15), the characteristic density $\rho$ and velocity $V$ account for the disrupting aerodynamic force, while the surface tension $\sigma$ and the characteristic length scale $L$ account for the surface tension retaining force. The acceleration of gravity $g$ is included in Eq. (15) because in part of the horizontal flow data collected in Table 1 the liquid film is asymmetric with respect to the tube axis due to the action of gravity, as discussed in the previous section, and this asymmetry is likely to have an effect on the fluid-structure interaction. Assuming the wall shear stress to depend only on the surface tension and acceleration of gravity besides the characteristic density, the velocity and length scales here in Eqs. (14) and (15) can be regarded as a minimal model, a model that retains the essential physics of the problem and at the same time yields the maximum simplification possible. Minimal models are typically used as a starting point in mathematical modeling and are normally upgraded on an as-needed basis with the inclusion of additional influencing parameters to improve their accuracy and predictive capability. As will be shown, the proposed minimal models in Eqs. (14) and (15) fit well the annular flow experimental databank. Viscous dissipation is in principle present in the liquid film and in the gas core, as both contain a velocity gradient. Notably, however, the minimal models proposed here do not include any viscosity. The fact that the proposed minimal models fit the available data well without including any viscosity suggests that viscous dissipation is not a dominant dissipation mechanism for the available annular flow data, which notably are limited to macroscale tubes and channels. With small channels and microchannels (which we will cover in a future study), we expect viscous dissipation (notably in the liquid film) to become more important.

The characteristic scales for density $\rho$, velocity $V$ and length $L$ for use with Eqs. (14) and (15) are identified as follows. The theoretical starting point for predicting the pressure drop in channel two-phase flow is the conservation equation for the total linear momentum. Referring to steady-state flow conditions 
for a channel with uniform cross section along its axis, the conservation equation for the total linear momentum in its one-dimensional approximation reads as follows:

$$
-\frac{d P}{d z}=\frac{4 \tau_{w}}{d_{h y d}}+G^{2} \frac{d}{d z}\left(\frac{1}{\rho_{m}}\right)+\rho_{a v g} g \sin (\vartheta)=\frac{4 \tau_{w}}{d_{h y d}}+\frac{d}{d z}\left(\rho_{m} V_{m}^{2}\right)+\rho_{a v g} g \sin (\vartheta)
$$

where $P$ is the pressure, $z$ is the axial coordinate along the channel axis, $d_{h y d}$ is the channel hydraulic diameter (four times the channel flow area $A_{\text {flow }}$ divided by the wetted perimeter $P_{\text {wet }}$, i.e. $d_{\text {hyd }}=4 A_{\text {flow }}$ $P_{\text {wet }}^{-1}$ ), $\vartheta$ is the channel inclination angle with respect to the horizontal ( $\vartheta=0$ for horizontal flow, and positive angles denote upflow), while $\rho_{\text {avg }}$ and $\rho_{m}$ are the average cross sectional density and the momentum density, respectively. As can be noticed, Eq. (16) is formally applicable to both circular tubes and non-circular channels. The average cross sectional density $\rho_{\text {avg }}$ is defined as:

$\rho_{\text {avg }}=(1-\varepsilon) \rho_{l}+\varepsilon \rho_{g}$

where $\varepsilon$ is the cross sectional void fraction in the channel. The momentum density $\rho_{m}$ is given as:

$$
\rho_{m}=\left[\frac{(1-e)^{2}(1-x)^{2} x}{(1-\varepsilon) x \rho_{l}-e \varepsilon(1-x) \rho_{g}}+\frac{e x(1-x)+x^{2}}{\varepsilon \rho_{g}}\right]^{-1}
$$

It is worth noting that in deriving the momentum density expression above, the slip between the carrier gas core and the entrained liquid droplets has been neglected, as is typically done in the analysis of annular flows. Within the limits of the present annular flow databank, the momentum density is always smaller than the average cross sectional density, and the difference between the two densities is typically within $30-40 \%$. The momentum velocity $V_{m}$ is defined as:

$$
V_{m}=\frac{G}{\rho_{m}}
$$

As can be seen in Eq. (16), the product of the momentum density $\rho_{m}$ times the square of the momentum velocity $V_{m}$ represents the specific kinetic energy $\left(\mathrm{Jm}^{-3}\right)$ of the two-phase flow that is changing as consequence of the acceleration/deceleration of the flow along the channel, so that the momentum density and the momentum velocity are an average density and an average velocity for the two-phase flow that together determine the specific kinetic energy of the flow, as it appears in the linear momentum conservation equation for the two-phase flow. 
The conservation equation for the total linear momentum in Eq. (16) can be written in dimensionless form as:

$-\frac{d P^{+}}{d z^{+}}=2 f_{t p}+\frac{d}{d z^{+}}\left(\frac{1}{\rho_{m}^{+}}\right)+\frac{1}{F r_{t p}}$

where $P^{+}$is the dimensionless pressure, $z^{+}$is the dimensionless axial coordinate along the channel axis, and $\rho_{m}{ }^{+}$is the dimensionless momentum density. In particular, the channel hydraulic diameter $d_{h y d}$ is used as the length scale in deriving Eq. (20), as normally done in the two-phase flow literature. The two-phase Fanning friction factor $f_{t p}$ and the two-phase Froude number $F r_{t p}$ are:

$$
\begin{aligned}
& f_{t p}=\frac{2 \tau_{w}}{\rho_{m} V_{m}^{2}} \\
& F r_{t p}=\frac{\rho_{m} V_{m}^{2}}{\rho_{a v g} g \sin (\vartheta) d_{h y d}}
\end{aligned}
$$

As can be seen, the conservation equation for the total linear momentum written in dimensionless form in Eq. (20) shows that in the modeling of the fluid-structure interaction the natural scales for density, velocity and length in two-phase flows are the momentum density $\rho_{m}$, the momentum velocity $V_{m}$ and the channel hydraulic diameter $d_{h y d}$, respectively. Accordingly, the minimal models in Eqs. (14) and (15) become:

$\tau_{w}=\tau_{w}\left(\rho_{m}, V_{m}, d_{\text {hyd }}, \sigma\right)$ Vertical upflow

$$
\tau_{w}=\tau_{w}\left(\rho_{m}, V_{m}, d_{h y d}, \sigma, g\right) \text { Horizontal flow }
$$

Applying dimensional analysis to Eqs. (23) and (24) yields:

$$
\begin{aligned}
& f_{t p}=f_{t p}\left(W e_{m}\right) \quad \text { Vertical upflow } \\
& f_{t p}=f_{t p}\left(W e_{m}, F r_{m}\right) \text { Horizontal flow }
\end{aligned}
$$

where $f_{t p}$ is the two-phase Fanning friction factor defined in Eq. (21), while $W e_{m}$ and $F r_{m}$ are:

$$
\begin{aligned}
& W e_{m}=\frac{\rho_{m} V_{m}^{2} d_{h y d}}{\sigma} \\
& F r_{m}=\frac{V_{m}^{2}}{g d_{h y d}}
\end{aligned}
$$


As can be seen, $W e_{m}$ is formally a Weber number while $F r_{m}$ is formally a Froude number: since they are based on the momentum density $\rho_{m}$ and momentum velocity $V_{m}$, they will be referred to as the momentum Weber number and the momentum Froude number, respectively. These dimensionless numbers have been derived specifically to analyze the fluid-structure interaction in annular two-phase flows. Within the limits of the present study, the momentum Weber number $W e_{m}$ captures the aerodynamic interaction between the liquid film and the gas core, while the momentum Froude number $F r_{m}$ takes into account the effect of gravity on the liquid film distribution in the channel cross section for horizontal flows.

The two-phase Fanning friction factor calculated for the data in Table 1 generated in adiabatic flow conditions with vertical tubes and annuli (3418 data points) is displayed versus the momentum Weber number in Fig. 2. It is evident that the data cluster quite well, confirming the validity of the minimal model for vertical annular upflow proposed here. In particular, a simple power law seems appropriate to capture the trend in the data in Fig. 2 (similar to single-phase turbulent flows singular dependence on the Reynolds number), so that the final form of Eq. (25) that fits the present databank (3418 data points for adiabatic flow in vertical tubes and annuli) is the following:

$$
f_{t p}=0.2140 W e_{m}^{-0.3884} ; \quad 10^{2} \leq W e_{m} \leq 10^{5} \quad \text { Vertical upflow }
$$

Moving on to horizontal flows, it is well known that when the flow velocity is large enough, the effect of gravity on the flow becomes negligible and horizontal annular flows become axially symmetric. Accordingly, the asymptotic limit of Eq. (26) for large momentum Froude number values is:

$$
f_{t p}=f_{t p}\left(W e_{m}, F r_{m}\right) \rightarrow f_{t p}\left(W e_{m}\right) \approx 0.2140 W e_{m}^{-0.3884} \text { for } F r_{m} \rightarrow+\infty
$$

That is to say, when the momentum Froude number is large the channel inclination no longer affects the flow, and as a result the two-phase Fanning friction factor no longer depends on the momentum Froude number and tends to the expression valid for vertical upflow (within experimental errors). In the light of the asymptotic limit in Eq. (30), the ratio in Eq. (31) calculated for the data in Table 1 for adiabatic flow conditions with horizontal tubes (1639 data points) is displayed in Fig. 3 versus the momentum Froude number:

$$
\frac{f_{t p}}{0.2140 W e_{m}^{-0.3884}}
$$


As can be seen, the data cluster quite well, confirming the validity of the present approach for horizontal annular flow. In particular, the data in Fig. 3 depict a growing and saturating trend with increasing momentum Froude number $F r_{m}$ that can be easily captured with a rational power law expression, so that the final form of Eq. (26) that fits the present databank (1639 data points for adiabatic flow in horizontal tubes) is the following:

$$
f_{t p}=0.2140 W e_{m}^{-0.3884} \frac{0.1009 F r_{m}^{0.6425}}{1+0.1009 F r_{m}^{0.6425}} ; \quad F r_{m} \geq 3 \quad \text { Horizontal flow }
$$

As can be noticed, the rational term containing the momentum Froude number in Eq. (32) reproduces the growing and saturating trend depicted by the data in Fig. 3, and its value is 0.9 for $F r_{m}=10^{3}$ while it is practically $\approx 1$ for momentum Froude number values above about $\approx 10^{4}$. It follows that horizontal annular flows are symmetric for $F r_{m}$ above $\approx 10^{4}$, close to being symmetric for $F r_{m}$ in the range of $10^{3}$ to $10^{4}$, while the asymmetry in the liquid film distribution becomes significant below $F r_{m}=10^{3}$. It is worth highlighting that the rational term in Eq. (32) containing the momentum Froude number is bounded between 0 and 1 (as the momentum Froude number varies between $0^{+}$and $+\infty$ ). This implies that the gravity induced breaking of the cylindrical symmetry in the liquid film distribution along the tube perimeter is accompanied by a reduction of the two-phase friction factor, with respect to a comparable but symmetric annular flow. In other words, asymmetric annular flows have lower pressure gradients with respect to symmetric ones. When the liquid film distribution along the channel perimeter becomes asymmetric, the liquid film at the tube top and tube sides can become too thin to develop disturbance waves and participate in the entrainment process. The aerodynamic interaction between the liquid film and the gas core becomes correspondingly weaker at the tube top and tube sides, while remains strong at the tube bottom where the liquid film is thicker. The weakening of the aerodynamic interaction at the tube top and tube sides induced by the local gravity-driven thinning of the liquid film can explain the observed reduction in the friction factor.

The wall shear stress $\tau_{w}$ required as input to Eq. (21) to calculate the two-phase Fanning friction factor is calculated from the experimental data in Table 1 by integrating the conservation equation for linear momentum for the annular flow in Eq. (16) along the channel, yielding: 


$$
\tau_{w}=\frac{d_{h y d}}{4}\left\{\frac{\Delta P}{L}-\frac{G^{2}}{L}\left(\frac{1}{\rho_{m-o}}-\frac{1}{\rho_{m-i}}\right)-\frac{1}{2}\left(\rho_{\text {avg }-i}+\rho_{\text {avg }-o}\right) g \sin \vartheta\right\}
$$

where $\Delta P$ is the measured pressure drop, $L$ is the distance between the pressure taps, $\rho_{m-i}$ and $\rho_{m-o}$ are the momentum densities calculated at the inlet and outlet pressure taps, while $\rho_{\text {avg-i }}$ and $\rho_{\text {avg-o }}$ are the average cross sectional densities calculated at the inlet and outlet pressure taps. As can be seen in Eq. (17) and Eq. (18), the void fraction $\varepsilon$ and the entrained liquid fraction $e$ are needed as inputs to calculate the cross sectional density and the momentum density. In the present study, the void fraction is predicted using the annular flow method of Cioncolini and Thome (2012b) already presented in Eqs. (9)-(10), while the entrained liquid fraction is predicted according to Cioncolini and Thome (2012a) as follows:

$$
e=\left(1+279.6 W e_{c}^{-0.8395}\right)^{-2.209}
$$

where the core flow Weber number $W e_{c}$ and the droplet laden gas core density $\rho_{c}$ are defined as:

$$
W e_{c}=\frac{\rho_{c} J_{g}^{2} d}{\sigma} ; \quad \rho_{c}=\frac{x+e(1-x)}{\frac{x}{\rho_{g}}+\frac{e(1-x)}{\rho_{l}}}
$$

As can be noticed, the core flow Weber number and the core flow density in Eq. (35) are slightly simplified with respect to the expressions in Eqs. (3) and (4) previously discussed. As explained in Cioncolini and Thome (2012a), these simplifications do not penalize significantly the prediction accuracy while making this entrained liquid fraction prediction method simpler to use and fully stand-alone, a significant advantage in practical design applications. As can be seen in Eq. (35), the core flow density $\rho_{c}$ depends on the entrained liquid fraction $e$, so that in principle an iterative calculation would be required to resolve these expressions. As described by Cioncolini and Thome (2012a), however, the method was implemented with a two-step explicit predictor-corrector scheme to simplify the procedure.

In conclusion, the new method proposed here for predicting the pressure gradient in annular two-phase flows reads as follows:

$$
-\frac{d P}{d z}=2 f_{t p} \frac{\rho_{m} V_{m}^{2}}{d_{h y d}}+G^{2} \frac{d}{d z}\left(\frac{1}{\rho_{m}}\right)+\rho_{\text {avg }} g \sin (\vartheta)
$$

The two-phase Fanning friction factor $f_{t p}$ is predicted with Eq. (29) for vertical tubes and channels, while Eq. (32) is used for horizontal flows. The momentum Weber number and the momentum Froude number are defined in Eqs. (27) and (28), while the average density and the momentum density are calculated 
according to Eqs. (17) and (18), respectively. For the reader's convenience, these equations are reproduced below:

$f_{t p}=0.2140 W e_{m}^{-0.3884} ; \quad 10^{2} \leq W e_{m} \leq 10^{5} \quad$ Vertical upflow

$f_{t p}=0.2140 W e_{m}^{-0.3884} \frac{0.1009 F r_{m}^{0.6425}}{1+0.1009 F r_{m}^{0.6425}} ; \quad F r_{m} \geq 3$ Horizontal flow

$W e_{m}=\frac{\rho_{m} V_{m}^{2} d_{h y d}}{\sigma} ; \quad F r_{m}=\frac{V_{m}^{2}}{g d_{h y d}} ; \quad V_{m}=\frac{G}{\rho_{m}}$

$\rho_{\text {avg }}=(1-\varepsilon) \rho_{l}+\varepsilon \rho_{g}$

$\rho_{m}=\left[\frac{(1-e)^{2}(1-x)^{2} x}{(1-\varepsilon) x \rho_{l}-e \varepsilon(1-x) \rho_{g}}+\frac{e x(1-x)+x^{2}}{\varepsilon \rho_{g}}\right]^{-1}$

The void fraction and the entrained liquid fraction are predicted according to Cioncolini and Thome (2012a, 2012b). As can be seen, this new prediction method is very simple to implement and use, is physically plausible and is formally applicable to both circular tubes and non-circular channels, provided that the hydraulic diameter is used in place of the tube diameter.

\section{Results and discussion}

The predictions of the new pressure drop method are compared with the measured data for adiabatic annular flow (5057 data points) from Table 1 in Figs. 4-5, while the statistical comparison between measurements and predictions is reported in Table 2. In order to put the present results into perspective, Table 2 also includes the predictions of 19 existing pressure drop correlations: 12 different implementations of the homogeneous model (with two-phase viscosity defined according to McAdams et al. (1942), Cicchitti at al. (1960), Dukler et al. (1964), Owens (1961), Beattie and Whalley (1982), Davidson et al. (1943), Garcia et al. (2003), Akers et al. (1958) and Awad and Muzychka (2008)), plus the widely used correlations of Lockhart and Martinelli (1949), Martinelli and Nelson (1948), Baroczy (1966) and Chisholm (1973), Friedel (1979), Müller-Steinhagen and Heck (1986), Lombardi and Carsana (1992) and Shannak (2008). A comprehensive account of these pressure drop correlations can be found in Thome and Cioncolini (2015). As can be seen in Table 2, the new prediction method proposed here fits the available adiabatic flow data better than the other methods considered, with a mean absolute 
percentage error of $12.9 \%$ and 7 points out of 10 captured to within $\pm 15 \%$. Within the limits of the present study, therefore, the aerodynamic interaction between the liquid film and the gas core seems to control the fluid-structure interaction in annular flows, and this is apparently well captured by the momentum Weber number. The momentum Froude number, on the other hand, comes into play in horizontal flows when the liquid film is asymmetric in the tube cross section. The best predictions by existing methods are given by the homogeneous model with two-phase viscosity defined according to Owens (1961), and by the correlations of Müller-Steinhagen and Heck (1986) and Friedel (1979). Finally, the predictions of the new pressure drop method are compared with the measured data for evaporating annular flow from Table 1 (1234 data points) in Fig. 6. In particular, these data have been generated with water evaporating in vertical tubes and annuli with electrical heating and uniform heat flux along the channel. Annuli, in particular, were tube-side heated while the rod was adiabatic. In these evaporative tests, the operating pressures were in the range of 4.1-9.1 MPa, mass fluxes ranged from 500 $\mathrm{kgm}^{-2} \mathrm{~s}^{-1}$ to $4557 \mathrm{kgm}^{-2} \mathrm{~s}^{-1}$, vapor qualities varied from 0.09 to 0.86 , and heat fluxes were within 5-4482 $\mathrm{kWm}^{-2}$, thus covering operating conditions of interest for high heat flux cooling applications. In the calculation the evaporative channel was discretized into equal length subchannels, and the new prediction method was applied to each subchannel to compute the local pressure drop, using local values of the thermophysical properties. Then, the calculated pressure drops for each subchannel were added to provide the total pressure drop for the whole channel. Notably, subchannels with a length of 20-25 diameters were found appropriate to yield discretization-independent pressure gradient predictions. As can be seen in Fig. 6 , the new pressure drop prediction method works fine for evaporating flows (mean absolute error of $11.2 \%$, and $74.6 \%$ of the data captured within $\pm 15 \%$ ). Within the limits of the present study, therefore, evaporation seems to have a negligible effect on the aerodynamic interaction between the liquid film and the gas core that controls the pressure gradient in annular flows, and the proposed pressure drop prediction method can therefore be applied to evaporative channel flows as well.

\section{Conclusions}

A new prediction method for the pressure drop in annular two-phase flow has been proposed. The new prediction method is based on the aerodynamic interaction between the liquid film and the gas core in annular flows, which is captured by the momentum Weber number. Notably, the new prediction method 
specifically takes into account the asymmetric liquid film distribution in the tube cross section that is induced by gravity in horizontal tubes operated at low mass flux, which is accounted for by the momentum Froude number. The underlying experimental database contains 6291 data points that cover horizontal and vertical tubes and annuli operated at both adiabatic and evaporating flow conditions, and covers operating conditions of interest for high heat flux cooling applications and for refrigeration and air conditioning. The new prediction method is very simple to implement and use, is physically sound, reproduces the available data better than existing correlations, and works also for evaporating flows and non-circular channels.

\section{Acknowledgements}

Professors A.W. Mauro and R. Revellin are gratefully acknowledged for sharing their pressure drop data.

\section{References}

Adorni, N., Casagrande, I., Cravarolo, L., Hassid, A., Pedrocchi, E., Silvestri, M., 1963. Further investigations in adiabatic dispersed flow: pressure drop and film thickness measurements with different channel geometries-analysis of the influence of geometrical and physical parameters. CISE Report R-53, Segrate, Italy.

Akers, W.W., Deans, H.A., Crosser, O.K., 1958. Condensing heat transfer within horizontal tubes. Chem. Eng. Prog. 54, 89-90.

Awad, M.M., Muzychka, Y.S., 2008. Effective property models for homogeneous two-phase flows. Exp. Therm. Fluid Sci. 33, 106-113.

Baroczy, C.J., 1966. A systematic correlation for two-phase pressure drop. Chem. Eng. Progr. Sym. Ser. $62,232-249$. 
Beattie, D.R.H., Whalley, P.B., 1982. Simple two-phase frictional pressure drop calculation method. Int. J. Multiphase Flow 8, 83-87.

Casagrande, I., Cravarolo, L., Hassid, A., Pedrocchi, E., 1963. Adiabatic dispersed two-phase flow: further results on the influence of physical properties on pressure drop and film thickness. CISE Report R-73, Segrate, Italy.

Charnay, R., Revellin, R., Bonjour, J., 2015. Discussion on the validity of prediction tools for two-phase flow pressure drops from experimental data obtained at high saturation temperatures. Int. J. Refrigeration $54,98-125$.

Chisholm, D., 1973. Pressure drop due to friction during the flow of evaporating two-phase mixtures in smooth tubes and channels. Int. J. Heat Mass Transfer 16, 347-358.

Cicchitti, A., Lombardi, C., Silvestri, M., Soldaini, G., Zavattarelli, R., 1960. Two-phase cooling experiments-pressure drop, heat transfer and burnout experiments. Energia Nucleare 7, 407-425.

Cioncolini, A., Thome, J.R., Lombardi, C., 2009a. Algebraic turbulence modeling in adiabatic gas-liquid annular two-phase flow. Int. J. Multiphase Flow 35, 580-596.

Cioncolini, A., Thome, J.R., Lombardi, C., 2009b. Unified macro-to-microscale method to predict twophase frictional pressure drops of annular flows. Int. J. Multiphase Flow 35, 1138-1148.

Cioncolini, A., Thome, J.R., 2010. Prediction of the entrained liquid fraction in vertical annular gas-liquid two-phase flow. Int. J. Multiphase Flow 36, 293-302.

Cioncolini, A, Thome, J.R., 2011. Algebraic turbulence modeling in adiabatic and evaporating annular two-phase flow. Int. J. Heat Fluid Flow 32, 805-817. 
Cioncolini, A., Thome, J.R., 2012a. Entrained liquid fraction prediction in adiabatic and evaporating annular two-phase flow. Nucl. Eng. Des. 243, 200-213.

Cioncolini, A., Thome, J.R., 2012b. Void fraction prediction in annular two-phase flow. Int. J. Multiphase Flow 43, 72-84.

Cioncolini, A., Thome, J.R., 2013. Liquid film circumferential asymmetry prediction in horizontal annular two-phase flow. Int. J. Multiphase Flow 51, 44-54.

Cioncolini, A., Del Col, D., Thome, J.R., 2015. An indirect criterion for the laminar to turbulent flow transition in shear-driven annular liquid films. Int. J. Multiphase Flow 75, 26-38.

Cioncolini, A., Thome, J.R., 2016. Annular flow: a mechanistic suite of co-validated methods for twophase flow and boiling/condensation heat transfer. HEFAT2016-12 $2^{\text {th }}$ International Conference on Heat Transfer, Fluid Mechanics and Thermodynamics, Torremolinos, Spain, 11-13 July 2016.

Cravarolo, L., Hassid, A., Pedrocchi, E., 1964. Further investigation on two-phase adiabatic annulardispersed flow: effect of length and some inlet conditions on flow parameters. CISE Report R-93, Segrate, Italy.

Davidson, W.F, Hardie, P.H., Humphreys, C.G.R., Markson, A.A., Mumford, A.R., Ravese, T., 1943. Studies of heat transmission through boiler tubing at pressures from 500 to 3000 Lbs. Trans. ASME 65, 553-591.

Dukler, A.E., Wicks, M., Cleveland, R.G., 1964. Frictional pressure drop in two-phase flow, Part A: a comparison of existing correlations for pressure loss and holdup and Part B: an approach through similarity analysis. AIChE J. 10, 38-51. 
Friedel, L., 1979. Improved friction pressure drop correlation for horizontal and vertical two-phase pipe flow. European Two-Phase Flow Group Meeting, paper E2, Ispra, Italy.

Garcia, F., Garcia, R., Padrino, J.C., Mata, C., Trallero, J.L., Joseph, D.D., 2003. Power law and composite power law friction factor correlations for laminar and turbulent gas-liquid flow in horizontal pipelines. Int. J. Multiphase Flow 29, 1605-1624.

Gaspari, G.P., Lombardi, C., Peterlongo, G., 1964. Pressure drops in steam-water mixtures. CISE Report R-83, Segrate, Italy.

Grauso, S., Mastrullo, R., Mauro, A.W., Thome, J.R., Vanoli, G.P., 2013. Flow pattern map, heat transfer and pressure drops during evaporation of R1234ze(E) and R134a in a horizontal, circular smooth tube: Experiments and assessment of predictive methods. Int. J. Refrigeration 36, 478-491.

Grauso, S., Mastrullo, R., Mauro, A.W., Vanoli, G.P., 2014. Two-phase adiabatic frictional pressure gradients for $\mathrm{R} 410 \mathrm{a}$ and $\mathrm{CO}_{2}$ in a macro channel: Experiments and a simplified prediction method for annular flow from low to medium reduced pressures. Exp. Therm. Fluid Sci. 52, 79-87.

Hinkle, W.D., 1967. A study of liquid mass transport in annular air-water flow. Ph.D. Thesis, MITMassachusetts Institute of Technology, Boston, USA.

Levy, S., 1999. Two-Phase Flow in Complex Systems. Wiley, New York.

Lockhart, R.W., Martinelli, R.C., 1949. Proposed correlation of data for isothermal two-phase twocomponent flow in pipes. Chem. Eng. Progr. 45, 39-48.

Lombardi, C., Carsana, C.G., 1992. A dimensionless pressure drop correlation for two-phase mixtures flowing upflow in vertical ducts covering wide parameter range. Heat Technol. 10, 125-141. 
Martinelli, R.C., Nelson, D.B., 1948. Prediction of pressure drop during forced-circulation boiling of water. Trans. ASME 70, 695-702.

Mauro, A.W., Cioncolini, A., Thome, J.R., Mastrullo, R., 2014. Asymmetric annular flow in horizontal circular macro-channels: basic modeling of the liquid film distribution and heat transfer around the tube perimeter in convective boiling, Int. J. Heat Mass Transfer 77, 897-905.

McAdams, W.H., Woods, W.K, Heroman, L.C, 1942. Vaporization inside horizontal tubes II-benzene-oil mixtures. Trans. ASME 64, 193-200.

Müller-Steinhagen, H., Heck, K., 1986. A simple friction pressure drop correlation for two-phase flow in pipes. Chem. Eng. Process. 20, 297-308.

Oliemans, R.V.A., Pots, B.F.M., Trompé, N., 1986. Modeling of annular dispersed two-phase flow in vertical pipes. Int. J. Multiphase Flow 12, 711-732.

Owens, W.L., 1961. Two-phase pressure gradient. ASME Int. Develop. Heat Transfer Part II, 363-368.

Shannak, B.A., 2008. Frictional pressure drop of gas liquid two-phase flow in pipes. Nuc. Eng. Des. 238, 3277-3284.

Silva Lima, R.J., Moreno Quiben, J., Thome, J.R., 2009. Flow boiling in horizontal smooth tubes: new heat transfer results for R134a at three saturation temperatures. Appl. Th. Eng. 29, 1289-1298.

Silvestri, M., Casagrande, I., Cravarolo, L., Hassid, A., Bertoletti, S., Lombardi, C., Peterlongo, G., Soldaini, G., Vella, G., Perona, G., Sesini, R., 1963. A research program in two-phase flow. CISE Report, Segrate, Italy. 
Steiner, D., 1987. Pressure drop in horizontal flow. Data Set No. 6 in: Multiphase Science and Technology, Vol. 3, Eds.: Hewitt, G.F., Delhaye, J.M., Zuber, N., Hemisphere, USA.

Thome, J.R., Cioncolini, A., 2015. Encyclopedia of Two-Phase Heat Transfer and Flow I, Set 1: Fundamentals and Methods, Volume 3: Flow Boling in Macro and Microchannels, World Scientific Publishing, Singapore.

Thome, J.R., Cioncolini, A., 2016. Unified modeling suite for two-phase flow, convective boiling, and condensation in macro- and micro-channels, Heat Transfer Eng. 37, 1148-1157.

Tong, L.S., Weisman, J., 1996. Thermal Analysis of Pressurized Water Reactors. American Nuclear Society, USA.

Wallis, G.B., 1961. Flooding velocities for air and water in vertical tubes. United Kingdom Atomic Energy Authority, Report AEEW-R-123, England.

Woldesemayat, M.A., Ghajar, A.J., 2007. Comparison of void fraction correlations for different flow patterns in horizontal and upward inclined pipes. Int. J. Multiphase Flow 33, 347-370.

Würtz, J., 1978. An experimental and theoretical investigation of annular steam-water flow in tubes and annuli at 30 and 90 bar. Risø National Laboratory, Report No. 372, Denmark.

Zhang, M., Webb, R.L., 2001. Correlation of two-phase friction for refrigerants in small diameter tubes. Exp. Therm. Fluid Sci. 25, 131-139. 


\section{Figure captions:}

Fig. 1. Selected histograms describing the experimental database in Table 1.

Fig. 2. Two-phase Fanning friction factor vs. momentum Weber number for the data in Table 1 generated in adiabatic flow conditions with vertical tubes and annuli (3418 data points).

Fig. 3. Ratio in Eq. (31) vs. momentum Froude number for the data in Table 1 generated in adiabatic flow conditions with horizontal tubes (1639 data points).

Fig. 4. Total pressure gradient: predictions of the new vertical upflow method vs. measured data from Table 1 for adiabatic flow through vertical tubes and annuli (3418 data points).

Fig. 5. Total pressure gradient: predictions of the new horizontal flow method vs. measured data from Table 1 for adiabatic flow through horizontal tubes (1639 data points).

Fig. 6. Total pressure gradient: predictions of the new vertical upflow method vs. measured data from Table 1 for evaporating flow through vertical tubes and annuli (1234 data points). 


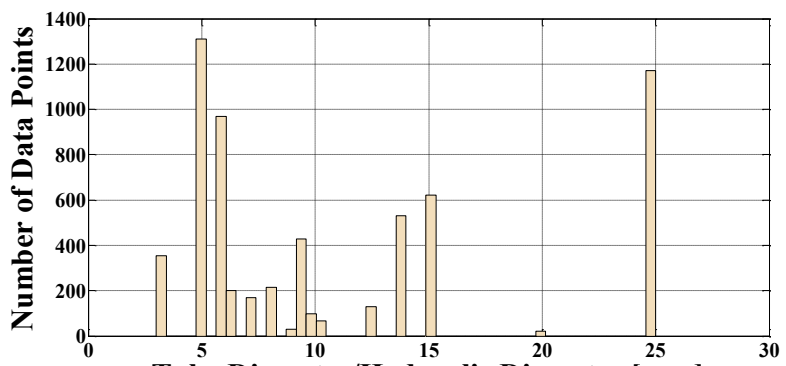

Tube Diameter/Hydraulic Diameter [mm]

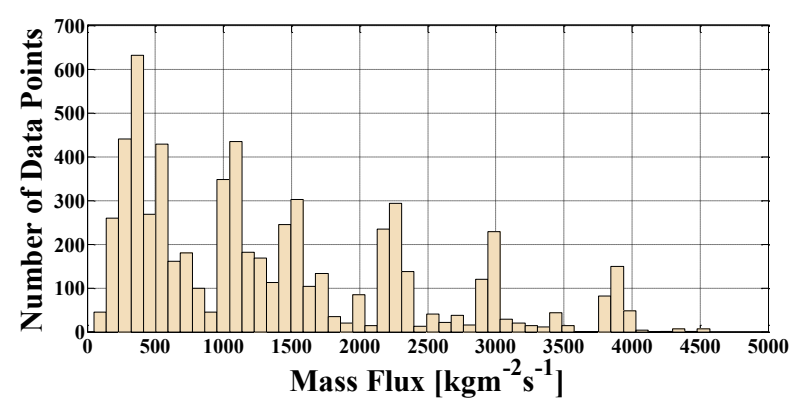

Evaporating Flow

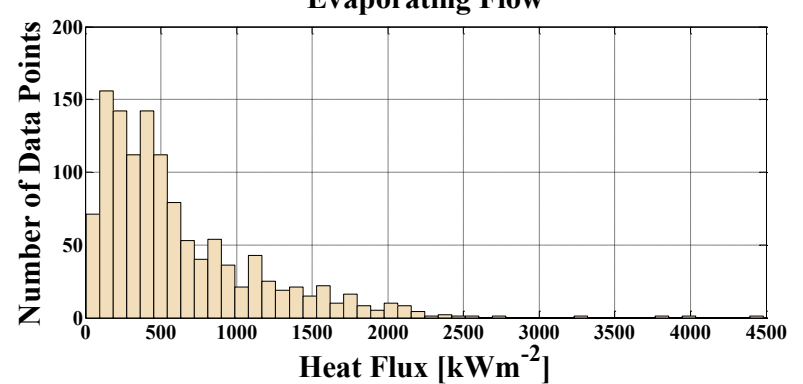

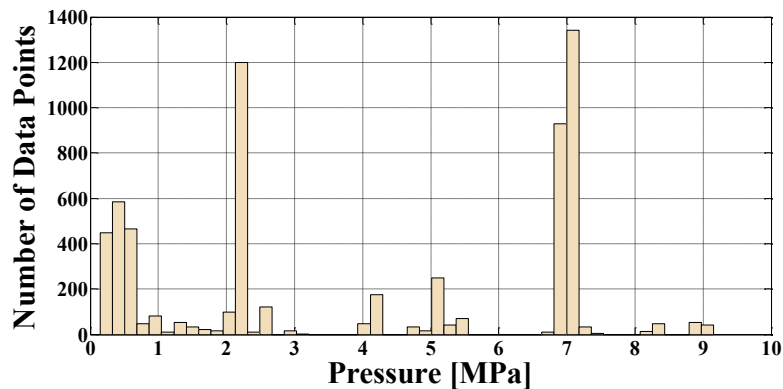
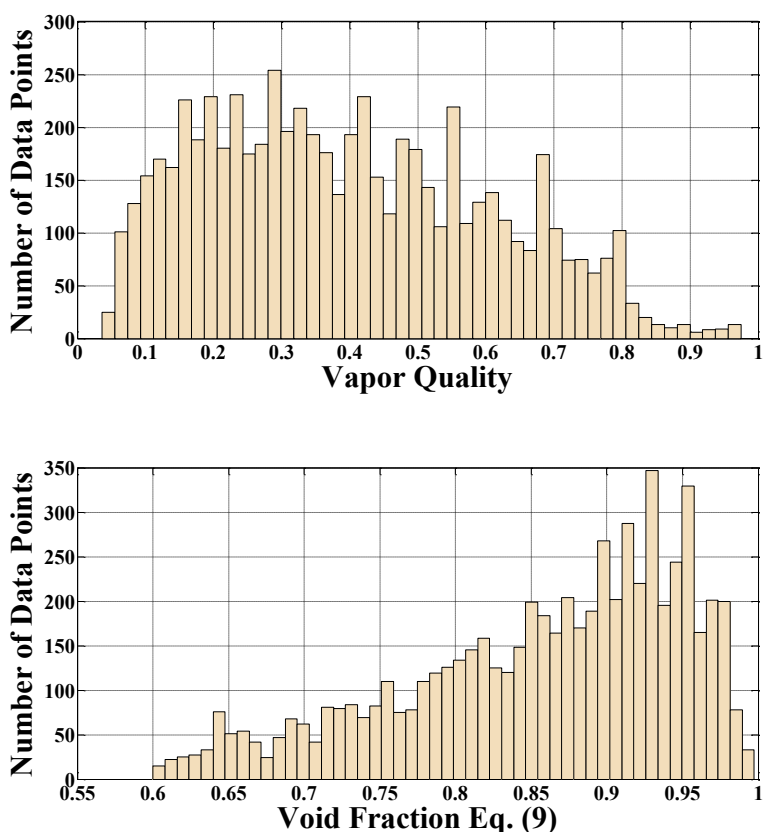

Fig. 1. Selected histograms describing the experimental database in Table 1. 

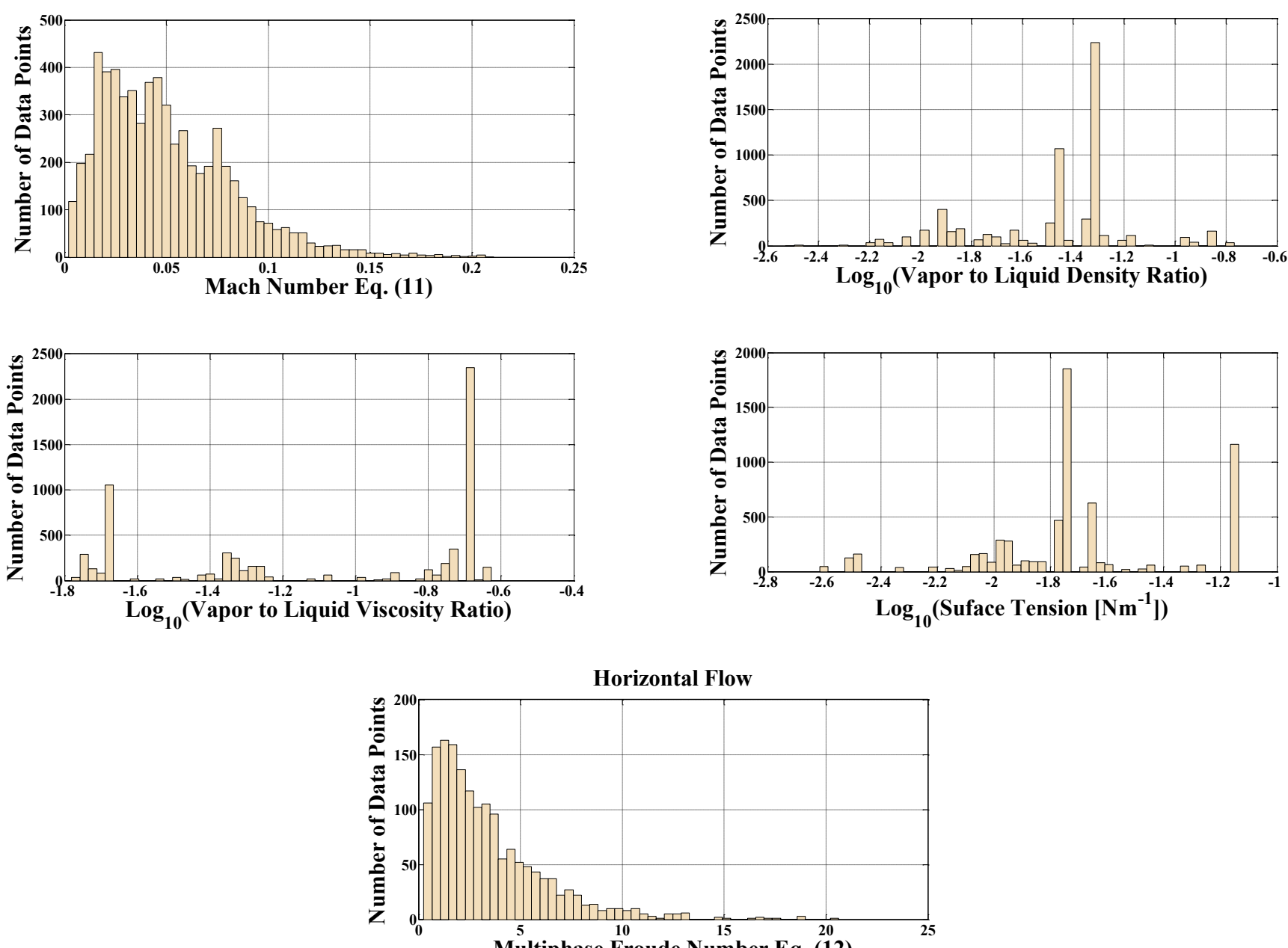

Multiphase Froude Number Eq. (12)

Fig. 1. (continued) 


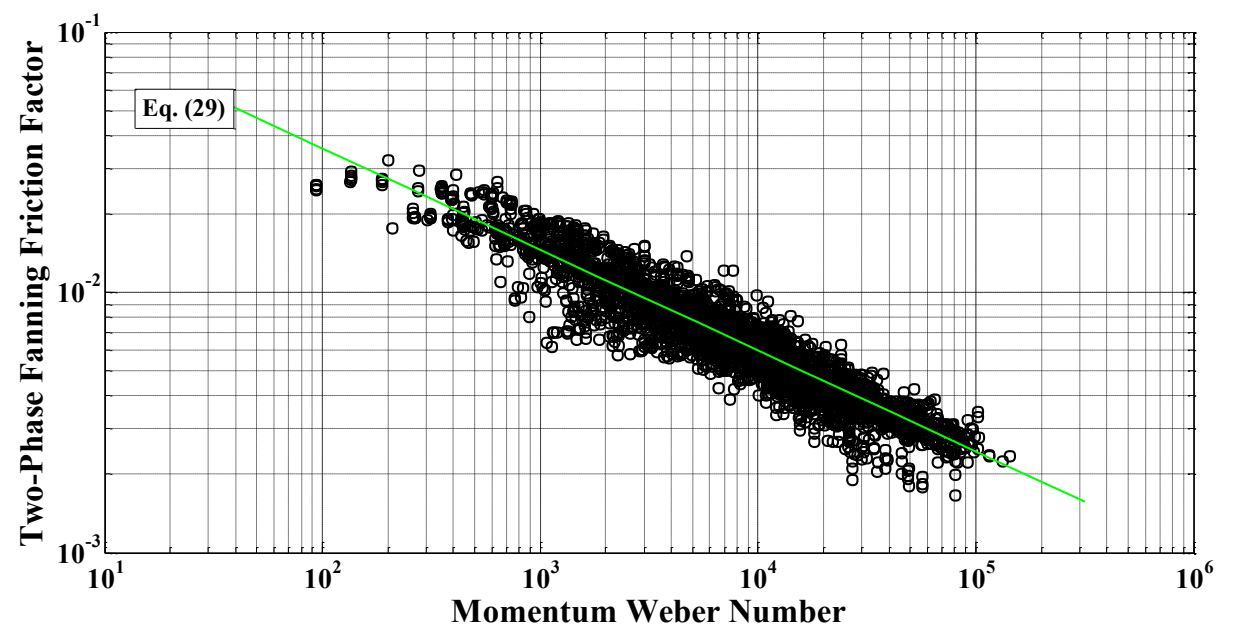

Fig. 2. Two-phase Fanning friction factor vs. momentum Weber number for the data in Table 1 generated in adiabatic flow conditions with vertical tubes and annuli (3418 data points). 


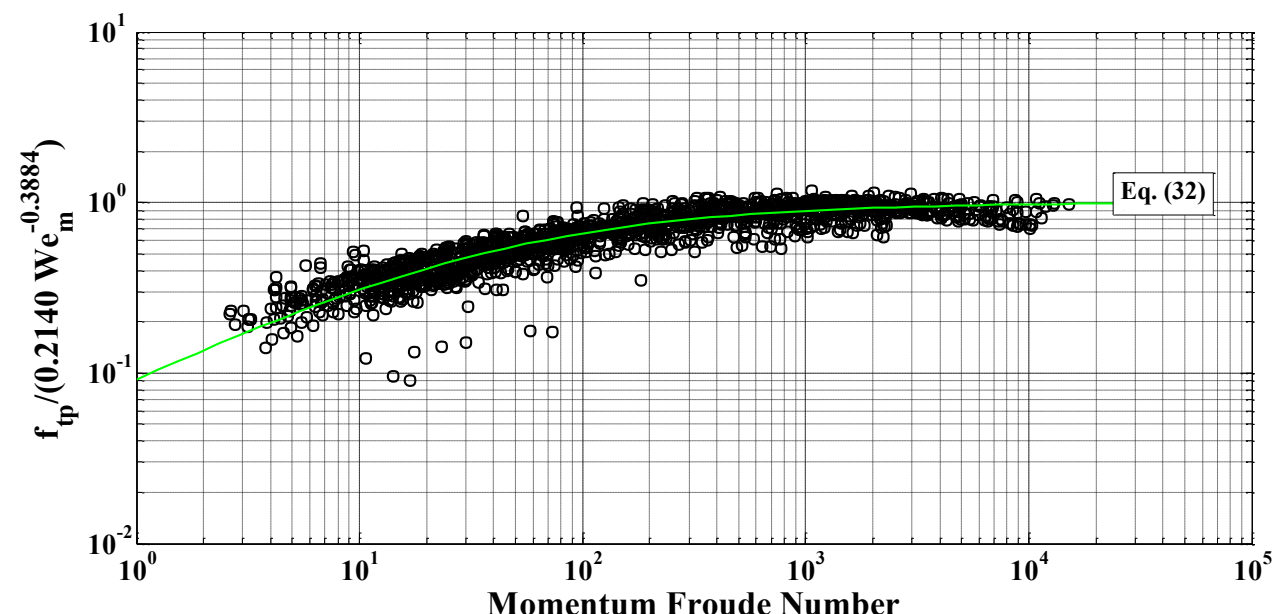

Fig. 3. Ratio in Eq. (31) vs. momentum Froude number for the data in Table 1 generated in adiabatic flow conditions with horizontal tubes (1639 data points). 


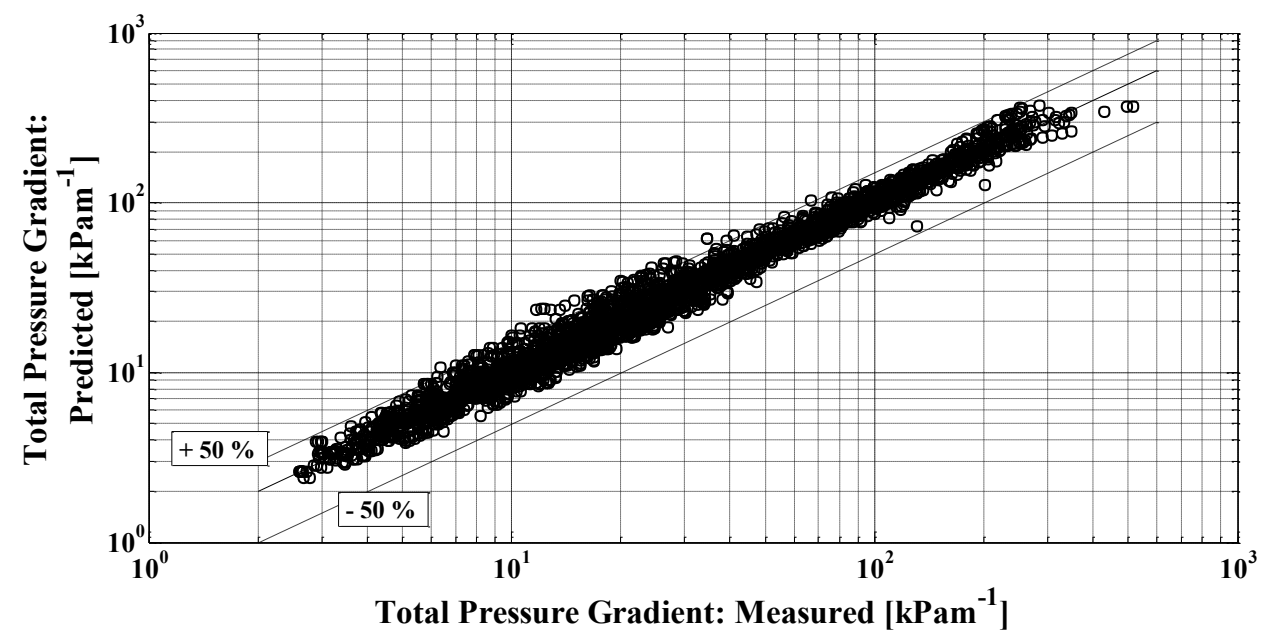

Fig. 4. Total pressure gradient: predictions of the new vertical upflow method vs. measured data from Table 1 for adiabatic flow through vertical tubes and annuli (3418 data points). 


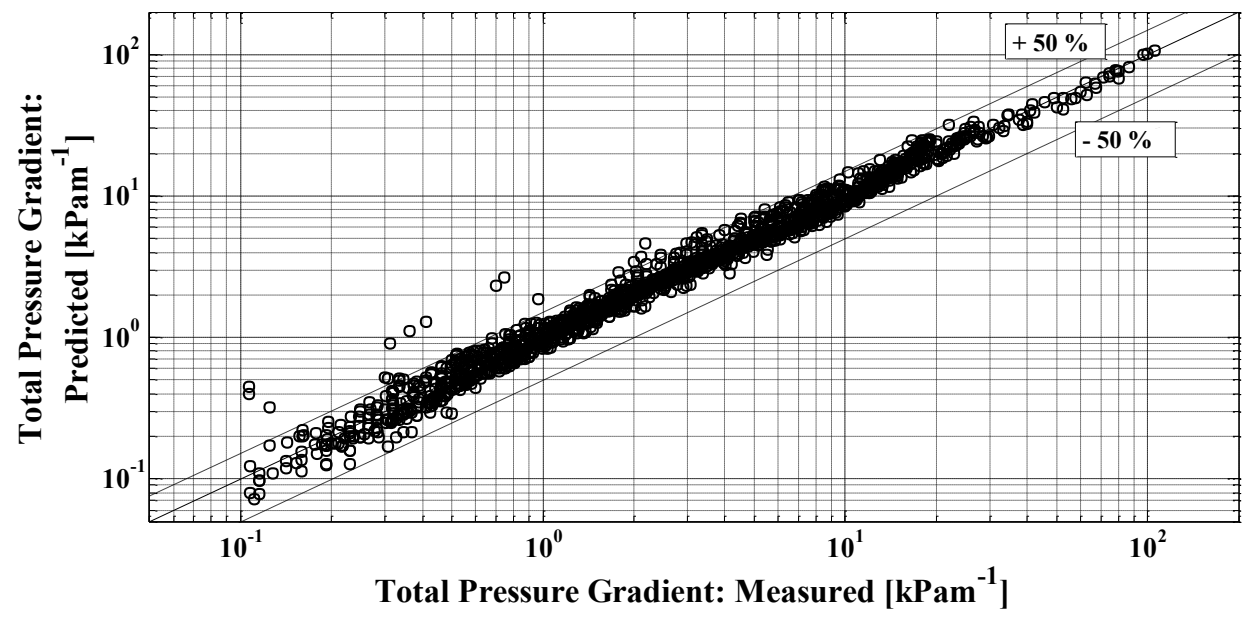

Fig. 5. Total pressure gradient: predictions of the new horizontal flow method vs. measured data from Table 1 for adiabatic flow through horizontal tubes (1639 data points). 


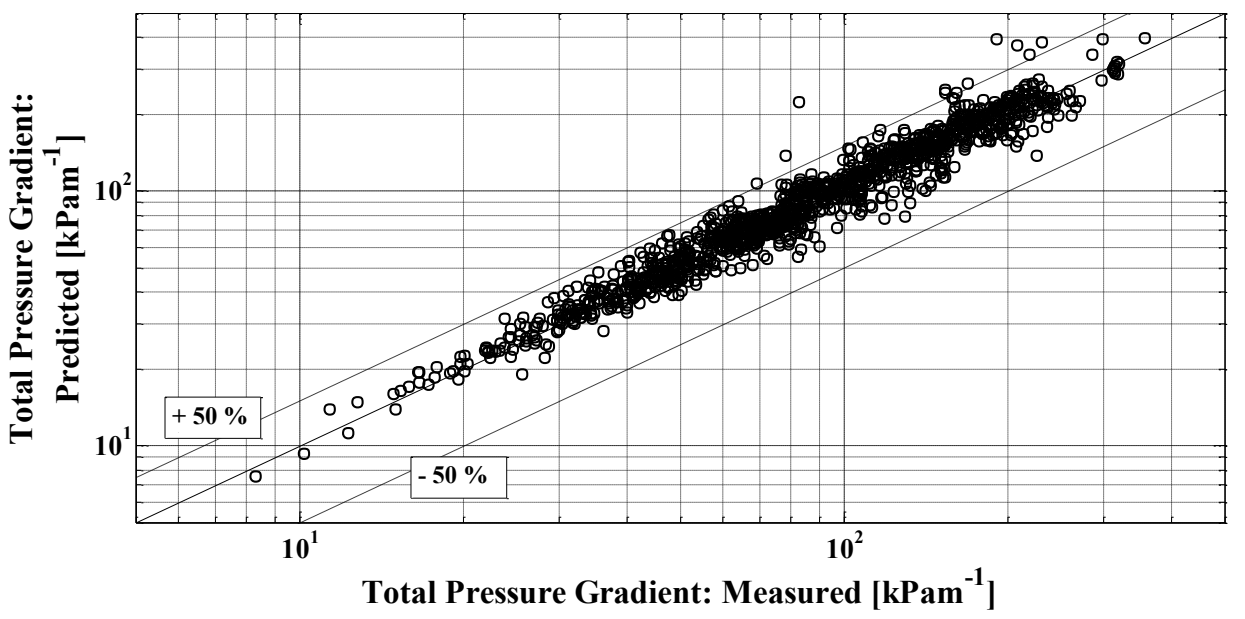

Fig. 6. Total pressure gradient: predictions of the new vertical upflow method vs. measured data from Table 1 for evaporating flow through vertical tubes and annuli (1234 data points). 
Table 1.

Experimental annular flow pressure drop data bank.

\begin{tabular}{|c|c|c|c|c|c|c|c|c|}
\hline Reference & Fluids & $d^{a}(\mathrm{~mm})$ & $P(\mathrm{MPa})$ & $G\left(\mathrm{kgm}^{-2} \mathrm{~s}^{-1}\right)$ & $x$ & $q_{w}\left(\mathrm{kWm}^{-2}\right)$ & $(1) /(2) /(3)$ & No. points \\
\hline Silvestri et al. (1963) & $\begin{array}{c}\mathrm{H}_{2} \mathrm{O} \\
\mathrm{H}_{2} \mathrm{O}-\mathrm{Ar} \\
\mathrm{H}_{2} \mathrm{O}+\text { alcohol-Ar }\end{array}$ & $3.25-25.0$ & $0.6-8.4$ & $280-4570$ & $0.06-0.84$ & $0-2226$ & ct,an $/ \uparrow / \mathrm{a}, \mathrm{h}$ & 1954 \\
\hline Gaspari et al. (1964) & $\mathrm{H}_{2} \mathrm{O}$ & $4.9-15.2$ & $2.0-9.2$ & $497-3949$ & $0.05-0.97$ & $0-4482$ & $\mathrm{ct} / \uparrow / \mathrm{a}, \mathrm{h}$ & 1358 \\
\hline Würtz (1978) & $\mathrm{H}_{2} \mathrm{O}$ & $9.0-20.0$ & $3.0-9.0$ & $400-3000$ & $0.08-0.70$ & $0-1500$ & ct,an $/ \uparrow / \mathrm{a}, \mathrm{h}$ & 147 \\
\hline Adorni et al. (1963) & $\mathrm{H}_{2} \mathrm{O}-\mathrm{Ar}$ & 15.1 & $0.60-2.2$ & $312-3420$ & $0.06-0.82$ & 0 & $\mathrm{ct} / \uparrow / \mathrm{a}$ & 129 \\
\hline Casagrande et al. (1963) & $\begin{array}{c}\mathrm{H}_{2} \mathrm{O}-\mathrm{N}_{2} \\
\mathrm{H}_{2} \mathrm{O}+\text { alcohol-Ar }\end{array}$ & $15.1-25.0$ & $0.30-2.4$ & $255-2880$ & $0.06-0.79$ & 0 & $\mathrm{ct} / \uparrow / \mathrm{a}$ & 115 \\
\hline Cravarolo et al. (1964) & $\begin{array}{l}\mathrm{H}_{2} \mathrm{O}-\mathrm{Ar} \\
\text { alcohol-Ar }\end{array}$ & $15.1 ; 25.0$ & $0.60-2.2$ & $266-2880$ & $0.04-0.81$ & 0 & $\mathrm{ct} / \uparrow / \mathrm{a}$ & 820 \\
\hline Hinkle (1967) & $\mathrm{H}_{2} \mathrm{O}$-Air & 12.6 & $0.2-0.6$ & $155-733$ & $0.15-0.71$ & 0 & $\mathrm{ct} / \uparrow / \mathrm{a}$ & 129 \\
\hline Silva Lima et al. (2009) & $\mathrm{R} 134 \mathrm{a}$ & 13.6 & $0.3-0.6$ & $308-520$ & $0.05-0.80$ & 0 & $\mathrm{ct} / \rightarrow / \mathrm{a}$ & 441 \\
\hline Steiner (1987) & R12 & 14.0 & $0.1-0.3$ & $50-246$ & $0.10-0.79$ & 0 & $\mathrm{ct} / \rightarrow / \mathrm{a}$ & 91 \\
\hline Zhang and Webb (2001) & $\begin{array}{l}\mathrm{R} 134 \mathrm{a} \\
\mathrm{R} 22\end{array}$ & $3.25-6.2$ & $1.0-1.9$ & $400-1000$ & $0.20-0.85$ & 0 & $\mathrm{ct} / \rightarrow / \mathrm{a}$ & 31 \\
\hline Charnay et al. (2015) & $\mathrm{R} 245 \mathrm{fa}$ & 3.0 & $0.4-2.0$ & $96-1200$ & $0.08-0.85$ & 0 & $\mathrm{ct} / \rightarrow / \mathrm{a}$ & 120 \\
\hline Grauso et al. (2013) & $\begin{array}{c}\text { R134a } \\
\text { R1234(ze) }\end{array}$ & 6.0 & $0.2-0.4$ & $149-514$ & $0.05-0.80$ & 0 & $\mathrm{ct} / \rightarrow / \mathrm{a}$ & 573 \\
\hline Grauso et al. (2014) & $\begin{array}{c}\mathrm{R} 410 \mathrm{a} \\
\mathrm{CO}_{2}\end{array}$ & 6.0 & $0.9-4.7$ & $152-513$ & $0.06-0.80$ & 0 & $\mathrm{ct} / \rightarrow / \mathrm{a}$ & 383 \\
\hline
\end{tabular}

${ }^{a}$ tube diameter for circular tubes, hydraulic diameter for annuli (four times the flow area divided by the wetted perimeter).

(1) Geometry of test section: $\mathrm{ct}=$ circular tube; an = annulus.

(2) Flow direction: $\uparrow=$ vertical upflow; $\rightarrow=$ horizontal flow.

(3) Type of test: $\mathrm{a}=$ adiabatic; $\mathrm{h}=$ heated.

Table 2 .

Statistical comparison between adiabatic pressure drop data from Table 1 (5057 data points) and correlation predictions.

\begin{tabular}{|c|c|c|c|c|c|}
\hline & $(1)$ & $(2)$ & (3) & $(4)$ & $(5)$ \\
\hline Homogeneous: McAdams et al. (1942) & 34.1 & 31.5 & 18.7 & 39.5 & 78.8 \\
\hline Homogeneous: Cicchitti et al. (1960) & 24.1 & 12.4 & 31.0 & 67.8 & 96.6 \\
\hline Homogeneous: Dukler et al. (1964) & 36.3 & 34.7 & 14.6 & 34.1 & 76.2 \\
\hline Homogeneous: Owens (1961) & 21.9 & 2.0 & 40.4 & 76.0 & 95.5 \\
\hline Homogeneous: Beattie and Whalley (1982) & 25.0 & 14.6 & 28.8 & 64.5 & 96.6 \\
\hline Homogeneous: Davidson et al. (1943) & 30.6 & 25.8 & 22.0 & 48.1 & 85.6 \\
\hline Homogeneous: Garcia et al. (2003) & 26.6 & 17.5 & 26.5 & 58.8 & 94.1 \\
\hline Homogeneous: Akers et al. (1958) & 26.9 & 19.2 & 25.9 & 55.8 & 95.5 \\
\hline Homogeneous: Awad and Muzychka (2008) No. 1 & 31.1 & 26.3 & 22.1 & 45.2 & 85.6 \\
\hline Homogeneous: Awad and Muzychka (2008) No. 2 & 256.5 & -254.8 & 16.3 & 26.8 & 39.0 \\
\hline Homogeneous: Awad and Muzychka (2008) No. 3 & 40.7 & 39.3 & 9.0 & 26.9 & 65.4 \\
\hline Homogeneous: Awad and Muzychka (2008) No. 4 & 27.7 & 21.0 & 24.1 & 53.1 & 96.1 \\
\hline Lockhart and Martinelli (1949) & 101.6 & -98.4 & 17.5 & 28.3 & 37.5 \\
\hline Martinelli and Nelson (1948) & 413.4 & -413.2 & 7.0 & 14.4 & 22.0 \\
\hline Baroczy (1966) and Chisholm (1973) & 47.1 & -29.7 & 34.3 & 57.9 & 75.8 \\
\hline Friedel (1979) & 23.6 & -1.3 & 42.8 & 75.5 & 91.7 \\
\hline Müller-Steinhagen and Heck (1986) & 22.1 & 6.0 & 38.3 & 70.2 & 96.8 \\
\hline Lombardi and Carsana (1992) & 55.0 & -52.2 & 49.1 & 72.2 & 81.6 \\
\hline Shannak (2008) & 27.1 & 19.6 & 26.8 & 57.6 & 92.7 \\
\hline Present study & 12.9 & -3.4 & 69.5 & 92.2 & 98.3 \\
\hline
\end{tabular}

(1)-Mean absolute percentage error (\%): $\frac{100}{n} \sum_{1}^{n} \frac{\left|(d P / d z)_{\exp }-(d P / d z)_{c a l}\right|}{(d P / d z)_{\exp }}$

(2)-Mean percentage error (\%): $\frac{100}{n} \sum_{1}^{n} \frac{(d P / d z)_{\exp }-(d P / d z)_{c a l}}{(d P / d z)_{\exp }}$

(3)-Percentage of experimental data captured within $\pm 15 \%$

(4)-Percentage of experimental data captured within $\pm 30 \%$

(5)-Percentage of experimental data captured within $\pm 50 \%$ 